\title{
The Impact of Demographic Characteristics and Risk Tolerance on Investors' Risk Perception and Portfolio Management
}

\author{
Taqadus Bashir, Sadia Shaheen, Zahra Batool, Mohsin \\ Hassan Butt, and Aaqiba Javed ${ }^{*}$
}

\begin{abstract}
Behavioral finance focuses on psychological factors-such as risk perception and portfolio management - that play a crucial role in investors' financial decisionmaking. This study investigates the effect of risk tolerance and demographic characteristics on risk perception and portfolio management, which, in turn, affect investors' decisions. Applying structural equation modeling to data collected from a sample of 120 respondents, we find a significant and positive relationship between risk perception and risk tolerance. Similarly, certain demographic characteristics, such as age and education, have a significant and positive relationship with risk perception while others, such as income and gender, have a significant but negative relationship with risk perception. Risk tolerance has a significant but negative relationship with portfolio management. Age, education, and income have a significant but negative relationship with portfolio management, while gender has a significant and positive relationship with portfolio management.
\end{abstract}

Keywords: Demographic characteristics, portfolio management, risk tolerance, risk perception.

\section{JEL classification: G11, G12, G19.}

\section{Introduction}

Factors that determine the risk-related attitudes of individual investors are of great concern in the field of behavioral finance, which looks at individual attributes (e.g., psychological) that play a key role in investment and financial decisions. Risk refers to the uncertainty associated with an outcome and arises when there are doubts about at least one possible outcome. Assessing the level of risk includes perceiving its state, which shows that the perception is explained by objective realism.

\footnotetext{
* Taqadus Bashir is an assistant professor at the Faculty of Management and Administration Sciences, University of Gujrat. Sadia Shaheen, Zahra Batool, Mohsin Hassan Butt, and Aaqiba Javed are postgraduate students at the institution.
} 
Sitkin and Pablo (1992) and Sitkin and Weingart (1995) argue that an individual's risk-taking action is affected mainly by risk perception and attitude. Weber and Hsee (1998) report that individual decision-making is influenced by risk perception in the case of investment decisions in the bonds market. Vlaev, Chater, and Stewart (2009) examine investors' preferences for distinct ways of transmitting risk-related information and note that risk presented in terms of an average maximum (best) or minimum (worst) is deemed preferable. Slovic (2000) points out that risk is inherently subjective: the process of risk perception connotes an objective situation that is itself formed by experience, emotions, and knowledge.

An investor who agrees to accept uncertainty at an extreme level when making a financial decision is termed risk-tolerant. This signifies the degree of unpredictability in returns that the individual is willing to tolerate. Risk tolerance is a significant factor in investment decisions. Individuals have to realistically consider their ability and willingness to bear ups and downs in the value of their investment. Investors who take on too much risk may panic and sell at the wrong time. The ability and willingness to accept failed investment decisions while waiting for the value of the investment to increase is part of risk tolerance. Investors who are averse to taking the chance that their investments might drop in price have little or no risk tolerance.

Prabhakaran and Karthika (2011) show that investors with a higher risk tolerance are more likely to make portfolio decisions. Risk tolerance thus has a direct impact on investors' investment decisions and determines the composition of various assets in the portfolio. Individual investors' risk tolerance may change over time since it is influenced by various exogenous factors, for example, major life experiences (Cordell, 2002).

Portfolio management involves constructing and maintaining a collection of investments. Funds are invested in distinct securities that minimize the portfolio's total risk while maximizing total returns. Portfolio management combines the weaknesses, strengths, threats, and opportunities associated with a certain choice of debt, equity, national and international situations, progress, and other tradeoffs. The challenge in portfolio management is to maximize returns at a given level of risk tolerance. This involves hedging risks to obtain the maximum possible return while minimizing the risk involved. In this context, Markowitz (1952) shows that portfolio managers diversify their portfolio on the basis of the variance and mean. 


\section{Significance of Study}

The aim of this study is to identify the effects of demographic characteristics and the level of risk tolerance on portfolio management and risk perception of different securities. The study is, therefore, significant for policymakers, financial advisors, bankers, and individual investors in the following ways. Policymakers adjust the risk and return associated with newly issued securities on the basis of risk perception and investors' risk tolerance. Financial advisors guide investors on the basis of their age, income, and risk tolerance, etc. Individual investors with a particular demographic characteristic need to understand risk perception and construct a portfolio that consists of a combination of beneficial securities.

The study aims to examine:

- The impact of demographic characteristics on investors' risk perception

- The effect of demographic characteristics on portfolio management

- The impact of risk tolerance on investors' risk perception

- The relationship between the degree of risk tolerance and portfolio management among investors and bankers.

\section{Literature Review}

Yordanova and Alexandrova-Boshnakova (2011) investigate the impact of gender on risk perception, propensity, and behavior, based on a sample of 382 Bulgarian entrepreneurs. Using Sitkin and Pablo's (1992) model of risk behavior and other studies on different cognitive factors, they find that gender has an indirect impact on risk perception through risk propensity and overconfidence. The gender effect on risk-taking tendency is mediated partly by age, outcome history, and risk preferences. Both male and female entrepreneurs had the same risk level but the latter had a lower risk propensity than their male counterparts.

Bashir, Ahmed et al. (2013) investigate the association between demographic variables and investment preferences in relation to stocks and gambling decisions among a sample of salaried finance teachers and bankers in Sialkot and Gujrat. The authors have analyzed risk variations among salaried individuals based on income, age, education level, and gender. Their findings show that females are more reluctant to take on risk than males. Younger as well as better-educated people are also willing to take more risk but hesitate due to resource scarcity and lack of investment 
opportunities. The study concludes that a negative relationship exists between gambling and risk taking when making investment decisions in a nonconducive economic environment.

Yao, Sharpe, and Wang (2011) look at the effects of generation, period, and age on risk tolerance, based on cross-sectional data for 19892007. They include "baby boomers" and members of the "silent" and Xgeneration in their sample of 21,167 respondents. The authors propose a hypothesis on the basis of their conceptual framework. Substantial risk, high risk, and low risk are taken as dependent variables while the independent variables include generation, survey year, economic factors, demographic characteristics, and perceptions. The study finds a negative relationship between age and risk tolerance: as age increases, the capacity to recoup losses decreases.

Hoffmann, Post, and Pennings (2013) examine how the perceptions of individual investors change, based on risk taking and trading behavior during the financial crisis of 2008/09. Using a sample of 1,510 clients with brokerage records, they collected data through a monthly questionnaire administered between April 2008 and March 2009. The reliability of the variables is determined using Cronbach's alpha. Their results indicate that investors' perceptions fluctuate significantly during a financial crisis. Risk perception and tolerance is less volatile than return-related expectations.

Wang, Shi, and Fan (2006) gauge investors' perceptions of risky investment in terms of psychological mechanisms in the Chinese stock market. The study aims to establish the risk perceptions associated with different types of information, cultural background, and the effect of asymmetric information. A 42-item questionnaire was distributed to 1,547 respondents from the Nan Fang Bond Company's sale departments. The authors use structural equation modeling (SEM) to generate the level of risk perception. They find a low level of subjective risk and a high level of objective risk. In the context of the Chinese stock market, the study recommends augmenting education, knowledge, and skills; strengthening the regularity of listed companies, and correcting the stock market's functional base.

Ramachandran, Rajeswari, and Chinnathambi (2011) study the factors affecting decision-making and risk perception among a sample of 100 investors in equity shares in India. Using primary data obtained from broker and investor profiles and the sample questionnaire results, and drawing on secondary sources, they assess investors' status in terms of 
demographic variables. The authors explain that information on these determinants contributes to making better investment decisions, but that more information on gender and religious factors was needed to explain investment decisions.

Larkin, Lucey, and Mulholland (2012) examine how age, gender, and education affect risk tolerance among investors in Ireland. Their methodology comprised socio-demographic questions that were asked to determine the behavior of individuals toward risk taking and 13 questions on financial risk tolerance in the form of a questionnaire. The authors conclude that age does not affect risk tolerance while gender does. Risk tolerance among investors has a negative relationship with home ownership and a positive relationship with household earnings and education level. Risk tolerance was found to increase with education level and decrease with homeownership.

Shafi et al. (2011) determine the relationship between investment behavior, risk perception, and risk attitude. They show how investors who are employees of an organization perceive risk relative to other investors. The study takes into account various factors, including personality traits (of investors), confidence level, period available in which to invest, and level of return. The authors find a strong association between risk perception and investors' behavior: investors who are more confident about an investment will more likely accept greater risk. Similarly, the more time available in which to invest, the more likely investors will be to invest in risky assets.

Van de Venter, Michayluk, and Davey (2012) review longitudinal studies on the shift in individual investors' risk tolerance scores over five years. The study attempts to determine which factors influence these changes and if risk tolerance changes over time. Analyzing data from the Smart Investor's Survey for the period of 2002-06, they apply a regression model to determine the outcomes. Their findings reveal that small annual changes occur in the financial risk tolerance of individual investors. A decline in household size also results in a slight decline in risk tolerance, while not using the services of a financial planner causes it to rise. Risk tolerance is not likely to alter substantially over the lifetime of an individual investor, implying that it is a stable attribute.

Bashir, Uppal et al. (2013) investigate the effect of risk tolerance with respect to stock index prices in the context of different demographic variables. Based on a sample of 106 respondents, including investors, 
bankers, and household individuals, they use a regression model and descriptive statistical tools to examine how far changes in stock indices affect risk tolerance. Risk tolerance is, therefore, the dependent variable and weekly and daily changes in KSE indices (from January 2012 to March 2013) are the independent variable. Household persons with higher incomes are shown to be more risk-tolerant than those with lower incomes.

Hariharan, Chapman, and Domian (2000) investigate the impact of the risk tolerance of investors nearing retirement on portfolio management. Using data collected in the first wave of the Health and Retirement Survey in 1992 (a sample of 15,000 individuals aged 51-61), they employ a linear regression model with T-bills as the dependent variable. The study finds that risk-tolerant investors nearing retirement did not decrease their bond allocation for the purpose of buying more stock.

Prabhakaran and Karthika (2011) assess the impact of risk perception and risk tolerance on investors' investment decisions. Applying the chi-square methodology to survey data collected from a sample of 200 respondents, they find that investors who showed a higher risk tolerance were more likely to make portfolio decisions. Male investors showed a greater preference for portfolio choices yielding higher returns.

\section{Hypothesis}

We put forward four hypotheses:

- H1: There is a significant relationship between demographic characteristics and risk perception.

- H2: Demographic characteristics affect investors' portfolio management.

- H3: There is a significant association between risk tolerance and risk perception.

- H4: There is a significant relationship between risk tolerance and investors' portfolio choices.

\section{Theoretical Framework and Methodology}

The present study is based on the theoretical framework illustrated in Figure 1.

Our objective was to investigate the impact of demographic characteristics (age, gender, education level, and income) and risk tolerance 
on risk perception and portfolio management. A 26-item questionnaire was administered to a sample of 140 respondents, including investors, bankers, finance students, and teachers, in different cities in Punjab. Of these, we received 120 responses.

The questionnaire (see Appendix) comprised four sections: (i) age, gender, marital status, education level, and occupation; (ii) risk tolerance (six items), (iii) risk perception (nine items), and (iv) portfolio management (six items). The sample included 75 males and 45 females; 70 respondents were married and the remaining single. Out of 120 respondents, 70 were 40-50 years old and the remaining under 40. Thirty respondents had an MBA, 20 had an MCom degree, and the remaining were graduates.

Figure 1: Theoretical framework

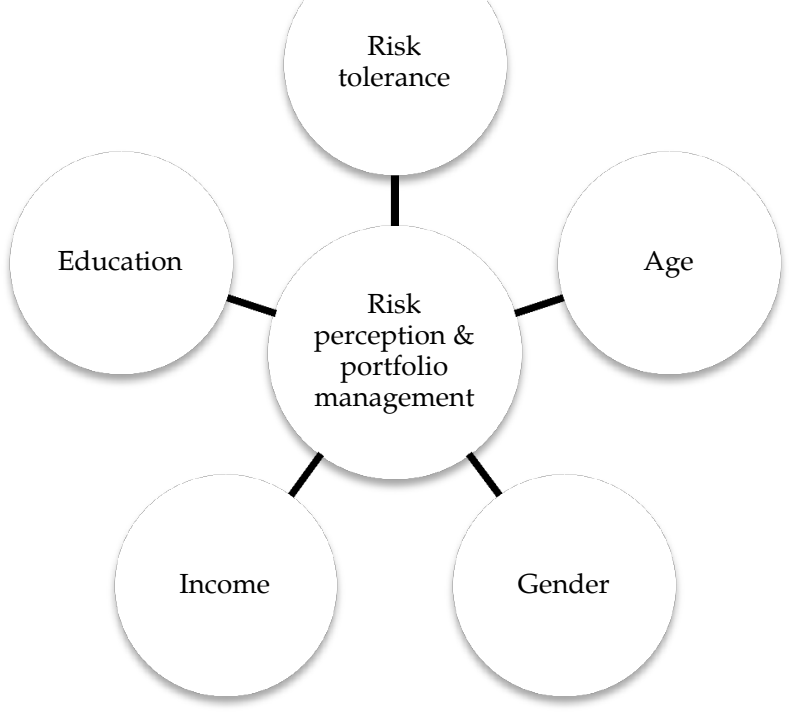

The normality of the dependent variables was verified using the Kolomogrov-Smirnov test. We applied Kendall's Tau-b correlation using SPSS 16, while the software AMOS 20 was used in SEM. Cronbach's alpha test was used to determine the validity and reliability of the data. Table 1 shows that all the variables used have an alpha value greater than 0.5. 
Table 1: Reliability test results

\begin{tabular}{llc}
\hline No. & \multicolumn{1}{c}{ Variable } & Cronbach alpha \\
\hline 1 & Risk perception & 0.536 \\
2 & Risk tolerance & 0.812 \\
3 & Portfolio management & 0.834 \\
\hline
\end{tabular}

Source: Authors' calculations.

\section{Results and Analysis}

Table 2 shows that demographic characteristics and risk tolerance have a significant relationship with risk perception and portfolio management. The correlation is significant at the level of 0.01 . Risk tolerance has a strong and highly significant positive relationship $\left(0.300^{* *}\right)$ with risk perception. Age and education have a highly significant positive relationship at the level of $0.189^{*}$ and $0.200^{*}$, respectively. Income and gender have a significant but negative relationship at the level of 0.05 with risk perception $\left(-0.008^{*}\right.$ and $-0.177^{*}$, respectively).

Table 2: Kendall's Tau-b correlation

\begin{tabular}{lcc}
\hline Variable & $\begin{array}{c}\text { Correlation } \\
\text { Risk perception }\end{array}$ & Portfolio management \\
\hline Risk tolerance & $0.300^{* *}$ & $-0.669^{* *}$ \\
Age & $0.189^{*}$ & $-0.215^{* *}$ \\
Gender & $-0.008^{*}$ & $0.280^{* *}$ \\
Education & $0.200^{*}$ & $-0.254^{* *}$ \\
Income & $-0.177^{*}$ & -0.150 \\
\hline
\end{tabular}

Note: ${ }^{*}=$ significant at 0.05 level, ${ }^{* *}=$ significant at 0.01 level.

Source: Authors' calculations.

Risk tolerance, age, and education have a strong and highly significant negative relationship with portfolio management $\left(-0.669^{* *}\right.$, $0.215^{* *}$, and $-0.254^{* *}$, respectively). Gender has a significant and positive relationship with portfolio management. The relationship between portfolio management and risk tolerance is highly significant but negative.

\subsection{SEM}

SEM is used to estimate the links between latent variables and their dimensions. Following the literature review and data analysis, we 
employed SEM to identify four important relationships between (i) risk tolerance and risk perception, (ii) risk tolerance and portfolio management, (iii) demographic characteristics and risk perception, and (iv) demographic characteristics and portfolio management (Figure 2).

Figure 2: SEM model

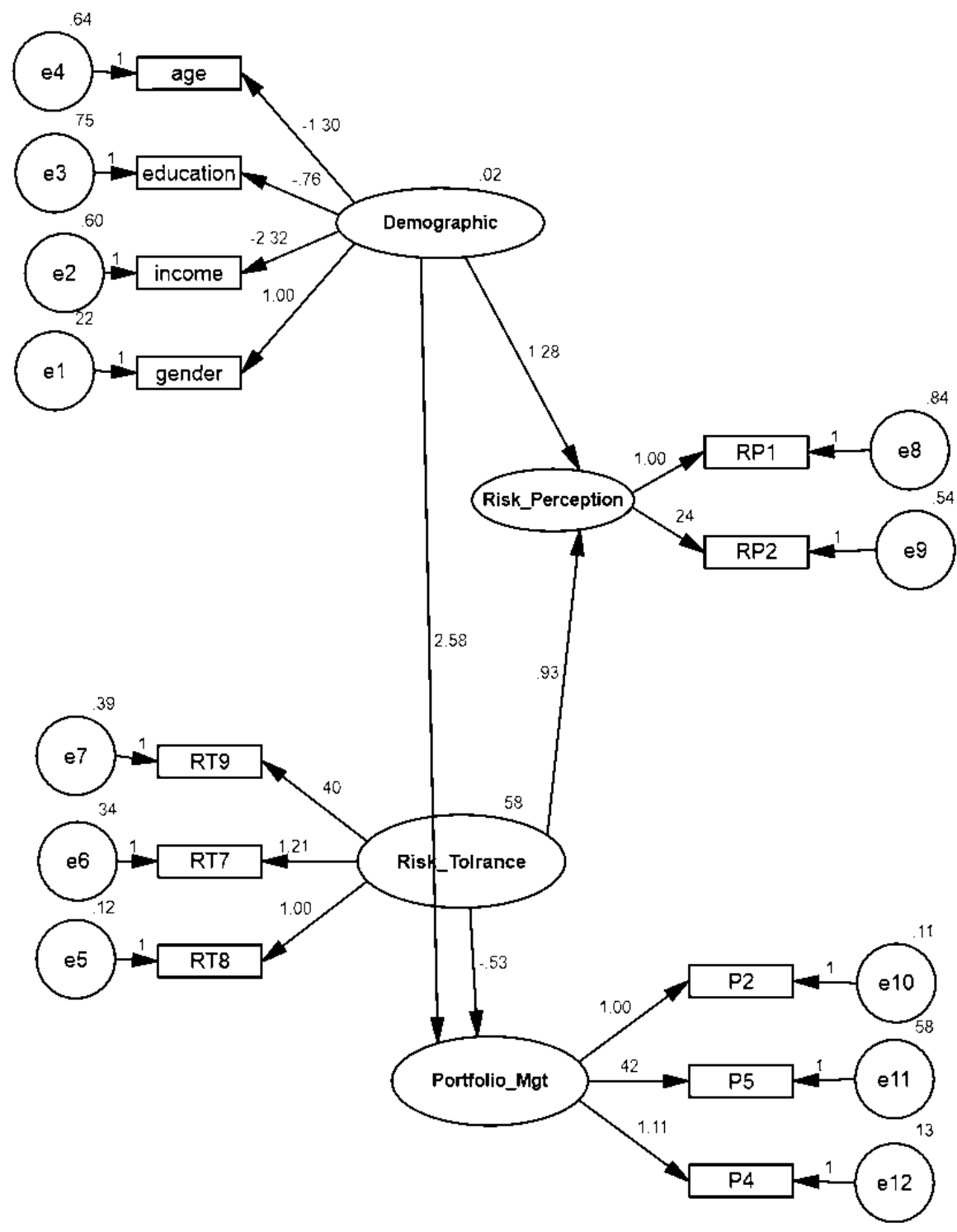

The analysis confirms the factors and yields a regression equation comprising risk perception and portfolio management as dependent variables denoted by $Y$ and demographic characteristics and risk tolerance 
as independent variables denoted by $X$. The level of significance is 0.05 with a confidence interval of 95 percent. The results indicate a significant relationship between the dependent and independent variables, where the $\mathrm{p}$-value is less than 0.05 .

$$
Y=\alpha+\beta \text { (risk tolerance })+\beta(\text { demographic characteristics })
$$

As per our hypothesis, risk perception and portfolio management are influenced by risk tolerance and demographic characteristics.

Table 3 gives the results of the SEM. The model meets all the criteria $(\mathrm{GFI}=0.908, \mathrm{AGFI}=0.970, \mathrm{NFI}=0.980, \mathrm{RFI}=0.949, \mathrm{TLI}=0.967$, and IFI $=$ 0.844 ) for fitness, with values higher than 0.9 except for IFI. The chi-square value is less than 3 with a p-value of 0.000 . The RMSEA value is 0.0251 , which is less than 0.08. All our hypotheses can, therefore, be accepted and the model is able to predict risk perception and portfolio management.

Table 3: Criteria for fitness of SEM

\begin{tabular}{llc}
\hline No. & \multicolumn{1}{c}{ Criteria } & Results \\
\hline 1 & Goodness of fit index (GFI) & 0.908 \\
2 & Adjusted goodness of fit index (AGFI) & 0.970 \\
3 & Normal fit index (NFI) & 0.980 \\
4 & Relative fit index (RFI) & 0.949 \\
5 & Incremental fit index (IF1) & 0.844 \\
6 & Tucker-Lewis index (TLI) & 0.967 \\
7 & Root mean square error of approximation (RMSEA) & 0.0251 \\
\hline
\end{tabular}

Source: Authors' calculations.

\section{Findings}

The results of the Kolomogrov-Smirnov test show that the data is not normal. We employ Kendall's Tau-b correlation test, which shows that the independent variables have a significant relationship with the dependent variables. The demographic characteristics gender and income have a negative and significant relationship while age and education have a positive and significant relationship with risk perception. Portfolio management has a significant and negative relationship with all the demographic characteristics, except gender where the relationship is positive. Risk tolerance has a negative and very strong relationship with portfolio management. 
On the basis of the given data, we find that all four hypotheses can be accepted: demographic characteristics and risk tolerance affect risk perception and portfolio management. Older respondents in the sample were more risk-averse than younger respondents (who may lack experience and prefer to invest in risky assets). Males were more likely to invest in risky assets than females. These findings are in line with Faff, Hallahan, and McKenzie (2011).

\section{Conclusion}

This study has attempted to determine which variables affect investors' risk perception and portfolio management and to what extent. We have looked at the impact of risk tolerance and demographic characteristics on portfolio management and risk perception. Our results have shown that acting on a risk is influenced by risk perception and riskrelated attitudes. Our conclusions are supported by Sitkin and Pablo (1992) and Sitkin and Weingart (1995).

We also find that risk tolerance and demographic characteristics (age, gender, and income), except education, affect risk perception and portfolio management. Investors in Pakistan are often not well educated and lack information on their investments, explaining why education does not seem to influence risk perception and portfolio management.

Investors tend to have little knowledge of portfolio management and how to minimize risk and maximize returns in Pakistan. They are only slightly familiar with the importance of risk and portfolio management. This reflects a need to improve the level of education and awareness among Pakistani investors. 


\section{References}

Alderfer, C. P., \& Bierman, H., Jr. (1970). Choices with risk: Beyond the mean and variance. Journal of Business, 43, 341-353.

Bashir, T., Ahmed, H. R., Jahangir, S., Zaigham, S., Saeed, H., \& Shafi, S. (2013). Investment preferences and risk level: Behavior of salaried individuals. IOSR Journal of Business and Management, 10(1), 68-78.

Bashir, T., Uppal, S. T., Hanif, K., Yaseen, S. M., \& Saraj, K. (2013). Financial risk-tolerant attitude: Empirical evidence from Pakistan. European Scientific Journal, 9(19), 200-209.

Cordell, D. M. (2002). Risk tolerance in two dimensions. Journal of Financial Planning, 15(5), 30-33.

Faff, R., Hallahan, T., \& McKenzie, M. (2011). Women and risk tolerance in a changing world. International Journal of Accounting and Information Management, 19(2), 100-117.

Hariharana, G., Chapman, K. S., \& Domian, D. L. (2000). Risk tolerance and asset allocation for investors nearing retirement. Financial Services Review, 9, 159-170.

Hoffmann, A., Post, T., \& Pennings, J. (2013). Individual investor perceptions and behavior during the financial crisis. Journal of Banking and Finance, 37, 60-74.

Klos, A., Weber, E. U., \& Weber, M. (2005). Investment decisions and time horizon: Risk perception and risk behavior in repeated gambles. Management Science, 51, 1777-1790.

Larkin, C., Lucey, B. M., \& Mulholland, M. (2012). Risk tolerance and demographic characteristics: Preliminary Irish evidence (Discussion Paper No. 406). Dublin, Ireland: Institute for International Integration Studies, Trinity College.

MacGregor, D., Slovic, P., Berry, M., \& Evensky, H. R. (1999). Perception of financial risk: A survey study of advisors and planners. Journal of Financial Planning, 12, 68-86.

Markowitz, H. (1952). Portfolio selection. Journal of Finance, 7(1), 77-91.

Prabhakaran, K., \& Karthika, P. (2011). A study on risk perception and portfolio management of equity investors in Coimbatore city. Journal of Management and Science, 1(2), 1-13. 
Ramachandran, T., Rajeswari, P. S., \& Chinnathambi, S. (2011, October). Investment behavior and risk-return perception of investors in equity shares. Paper presented at the 2011 International Research Conference and Colloquium on Contemporary Research Issues and Challenges in Emerging Economies, Universiti Tun Abdul Razak, Kuala Lumpur, Malaysia.

Shafi, H., Akram, M., Hussain, M., Sajjad, S. I., \& Rehman, K. (2011). Relationship between risk perception and employee investment behavior. Journal of Economics and Behavioral Studies, 3(6), 345-351.

Sitkin, S. B., \& Pablo, A. L. (1992). Reconceptualizing the determinants of risk behavior. Academy of Management Review, 17(1), 9-38.

Sitkin, S. B., \& Weingart, L. R. (1995). Determinants of risky decisionmaking behavior: A test of the mediating role of risk perceptions and propensity. Academy of Management Journal, 38(6), 1573-1592.

Slovic, P. (2000). The perception of risk. London, UK: Earthscan Publications.

Van de Venter, G., Michayluk, D., \& Davey, G. (2012). A longitudinal study of financial risk tolerance. Journal of Economic Psychology, 33(4), 794-800.

Vlaev, I., Chater, N., \& Stewart, N. (2009). Dimensionality of risk perception: Factors affecting consumer understanding and evaluation of financial risk. Journal of Behavioral Finance, 10, 158-181.

Wang, X. L., Shi, K., \& Fan, H. X. (2006). Psychological mechanisms of investors in Chinese stock markets. Journal of Economic Psychology, $27,762-780$.

Weber, E. U., \& Hsee, C. K. (1998). Cross-cultural differences in risk perception but cross-cultural similarities in attitudes towards risk. Management Science, 44, 1205-1217.

Yao, R., Sharpe, D. L., \& Wang, F. (2011). Decomposing the age effect on risk tolerance. Journal of Socio-Economics, 40, 879-887.

Yordanova, D. I., \& Alexandrova-Boshnakova, M. I. (2011). Gender effects on risk-taking of entrepreneurs: Evidence from Bulgaria. International Journal of Entrepreneurial Behavior and Research, 17(3), 272-295. 


\section{Appendix}

\section{Questionnaire}

Dear respondent your valuable opinion is required to conduct a research in finance. Please share your experience and opinion. This input of yours is for purely academic purpose.

Gender: City: Age:

1. Age from which you are investing:
a) $20-30$ b) $31-40$ c) $41-50$ d) $51-60$

2. What is your marital status?
a) Single b) Married

3. Occupation:
a) Government employee b) Private employee c) Own business

4. Education level:
a) Graduation
b) Master c) MS
d) $\mathrm{PhD}$

5. Employment status:
a) Employed b) Unemployed

6. Period of time you take to evaluate the performance of investment:
a) Monthly b) Quarterly c) Annually d) Over 5 yrs

7. What is your household's approximate annual gross income before taxes?
a) Less than 25,000 b) 25,000 to 49,999 c) 50,000 to 74,999 d) 75,000 to 99,999 e) greater than 100,000

8. Which type of investment you usually prefer?
a) Bonds b) Equities c) Bank deposits d) T-bills

9. Whose judgment analysis do you trust most while making investments?

a) Self b) Friends c) Expert opinion d) Media e) Broker 
10. You have poor knowledge about Company $X^{\prime}$ 's stock and are therefore uncertain about investing in it. Suddenly many of your coworkers and competitors start buying it. How would this affect your attitude towards ' $X$ '?

a) Positive b) Negative c) No change

11. On a scale of 1 to 7 what levels of risk do you undertake?

\begin{tabular}{lllllll}
\hline 1 & 2 & 3 & 4 & 5 & 6 & 7 \\
Low risk & $\begin{array}{l}\text { Medium } \\
\text { risk }\end{array}$ & High risk & Neutral & Low profit & $\begin{array}{l}\text { Medium } \\
\text { profit }\end{array}$ & High profit \\
\hline
\end{tabular}

12. What you perceive about the performance of investment in future:

a) Very Optimistic b) Positive c) Unsure d) Pessimistic

13. Between $\mathrm{P} / \mathrm{E}$ ratio and intrinsic value of a stock, which has more weightage in your investment decision?

a) $\mathrm{P} / \mathrm{E}$ ratio b) Intrinsic value c) Equal weightage

14. Do you save a part of your income for investing in the share market?

a) Yes b) Sometimes c) No

15. Can you name some stocks that have been a part of your portfolio in the past year like KSE/ISE/LSE?

16. What risk tolerance you show if the time of investment and response to market decline.

a) More willingness b) Less willingness c) Risk factor has no influence

17. On a scale of 1 to 5, how would you rate your knowledge on a relatively new field which studies financial decision making, called behavioral finance.

\begin{tabular}{llll}
\hline 1 Excellent 2 Very Good 3 Good & 4 Average 5 Poor
\end{tabular}

18. Do you favor investing in companies that are operating in Gujranwala and Gujrat, since we are more familiar with their operations?

a) Yes b) No c) Indifferent

19. Time horizon within which you withdraw your investment:

a) Currently b) Less than 3 years c) Between 6 to 15 years d) After 15 years 
20. You are on a TV game show and can choose one of the following. Which would you take?

a) $\$ 1,000$ in cash b) A $25 \%$ chance at winning $\$ 1,000$ c) A $50 \%$ chance at waiting $\$ 5,000 \mathrm{~d}) \mathrm{A} \%$ chance at winning $\$ 100,000$

21. Any portfolio activities you have made:

a) Yes b) No

22. When you think of the word "risk" which of the following words comes to mind first?
a) Loss
b) Uncertainty c) Opportunity d)
d) Thrill

23. What is your attitude about financial risk:

a) Diversified investment portfolio b) I only invested with extra money I can afford to loss c) Associated with playing in stock d) The higher the rate of return the greater the risk

24. Do you consider the past performance of a stock before investing in it?
a) Always
b) Sometimes c)
c) Often
d) Frequently e) Never

25. Do you end up sticking with a losing stock (wrong investment decision) for too long hoping for a reversal, or book profits in a winning stock and then felt you could have waited?
a) Always b) Sometimes c) Often d) Frequently e) Never

26. Have you put off an investment decision expecting new and favorable (positive) information release regarding the stock?
a) Always b) Sometimes c) Often d) Frequently e) Never 